\title{
Is stimulus competition an acquisition deficit or a performance deficit?
}

\author{
FRANCISCO ARCEDIANO and MARTHA ESCOBAR \\ Auburn University, Auburn, Alabama \\ and \\ RALPH R. MILLER \\ State University of New York, Binghamton, New York
}

\begin{abstract}
Traditionally, blocking (X-outcome, followed by XY-outcome, resulting in attenuated conditioned responding to $\mathrm{Y}$, relative to $\mathrm{XY}$-outcome alone) has been explained in terms of the $\mathrm{X}$-outcome association's preventing the acquisition of the $\mathrm{Y}$-outcome association. This view is challenged by models that view stimulus competition as a deficit in the expression of the acquired Y-outcome association. Here, we provide evidence that blocking is a performance deficit in which the Y-outcome association, the to-be-blocked stimulus, can affect behavioral control by the blocking stimulus (i.e., attenuate responding to $\mathrm{X}$ ). The results are discussed in terms of acquisition and performance models of stimulus competition.
\end{abstract}

Early psychological theories of learning (e.g., Bush \& Mosteller, 1951) assumed that spatiotemporal contiguity was both necessary and sufficient for learning to occur. That is, when two events were in a close temporal and spatial relationship, an association was presumably established between them, so that the presentation of one of the events would retrieve a representation of the other event. However, this view was challenged in the late 1960s by the analysis of stimulus competition. A frequently cited example of stimulus competition is the blocking effect (e.g., Kamin, 1968). Kamin observed that conditioned responding to a stimulus (Y) trained as a predictor of an outcome (e.g., an unconditioned stimulus [US]) was diminished (blocked) if this stimulus was presented during training in compound with another stimulus $(\mathrm{X})$ that had already been established as a good predictor of the occurrence of the impeding outcome (i.e., $\mathrm{X}$-US pairings, then XY-US pairings). The capacity to explain blocking and other stimulus competition effects separated early views of learning (e.g., Bush \& Mosteller, 1951) from a newer generation of associative models (e.g., Mackintosh, 1975; Pearce, 1987; Rescorla \& Wagner, 1972; Wagner, 1981).

These newer models of learning explain blocking on the basis of the assumption that redundant information is not encoded. Once an organism has learned that a stim-

Support for this research was provided by NIMH Grant 33881. We thank Jeffrey Amundson, Tom Beckers, Oskar Pineño, Gonzalo Urcelay, Koji Urushihara, and Daniel Wheeler for their comments on a preliminary version of this article. Thanks are also due Monica Zgola for her assistance with the collection of the data. Correspondence concerning this article should be addressed to R. R. Miller, Department of Psychology, SUNY-Binghamton, Binghamton, NY 13902-6000 (email: rmiller@binghamton.edu). ulus is a reliable predictor of an outcome, this stimulus will impede or block learning about other stimuli presented together with it as predictors of the same event. This framework, which we will hereafter call the informational hypothesis, challenged the assumption that contiguity was sufficient for learning to occur. According to the informational hypothesis, learning occurs only when one event nonredundantly predicts the occurrence of another. Thus, blocking reflects a deficit in the acquisition of an association between Y and the US. Other stimulus competition effects (e.g., overshadowing [Pavlov, 1927], the US-preexposure effect [Randich \& LoLordo, 1979], and the relative stimulus validity effect [Wagner, Logan, Haberlandt, \& Price, 1968]) are explained in a similar way by these associative theories.

The informational hypothesis view has been challenged since the mid-1980s by the comparator hypothesis (e.g., Denniston, Savastano, \& Miller, 2001; Miller \& Matzel, 1988). The comparator hypothesis differentiates between the processes of acquisition and production of a response. The model assumes that associations between stimuli are learned through contiguity and that, at each opportunity to respond, associations compete with each other to determine whether the stimulus will elicit a response. That is, contiguity is considered sufficient for learning to occur, but responding in the presence of a stimulus depends on a comparison at the time of each test trial between (1) the strength of the association between the test stimulus and the outcome and (2) the associative strength between the other (discrete or contextual) stimuli that were trained together with the test stimulus and the outcome. For example, in a blocking procedure (i.e., X-US followed by XY-US, testing on Y), the previously trained stimulus (X) does not prevent the acquisition of an association be- 
tween Y and the US; that is, the Y-US association is acquired through contiguity and independently of the effects of X. Rather, conditioned responding to Y is blocked because $\mathrm{X}$ has a stronger association to the US than does $\mathrm{Y}$. That is, responding to $\mathrm{Y}$ depends on a comparison between the degree to which Y signals the US and the degree to which other stimuli presented together with $\mathrm{Y}$ (in this case, $\mathrm{X}$ ) also signal the US. Activation of the US representation by the companion (comparator) stimuli attenuates responding based on the $\mathrm{Y}-\mathrm{US}$ association. ${ }^{1}$

To summarize, in the framework of the comparator hypothesis, blocking treatment results in the acquisition (but not expression) of an association between the blocked stimulus (Y) and the US. Thus, posttraining treatments that weaken the association between the blocking stimulus (X) and the US should enhance conditioned responding to Y, thereby revealing the otherwise latent association between Y and the US. There are many demonstrations of posttraining extinction of the competing stimulus's enhancing responding to the target stimulus in overshadowing (e.g., Kaufman \& Bolles, 1981; Larkin, Aitken, \& Dickinson, 1998; Matzel, Schachtman, \& Miller, 1985; Wasserman \& Berglan, 1998), relative stimulus validity (e.g., Cole, Barnet, \& Miller, 1995), and more recently, blocking (Arcediano, Escobar, \& Matute, 2001; Blaisdell, Gunther, \& Miller, 1999; but see Rauhut, McPhee, DiPietro, \& Ayres, 2000). These challenge the traditional view of stimulus competition as an acquisition failure and invite interpretations of stimulus competition in terms of failures to express acquired information. However, the recent emergence of modified versions of the Rescorla-Wagner (1972) model (e.g., Van Hamme \& Wasserman, 1994) and Wagner's (1981) SOP model (Dickinson \& Burke, 1996) allowed the informational view to account for changes in responding to the target stimulus (Y) following posttraining revaluation of the competing stimulus. The modified versions of the Rescorla-Wagner and SOP models share with their predecessors the general assumption that competition between stimuli reflects a failure to acquire an association between the target stimulus (Y) and the US. However, they differ from their predecessors in that they assume that the strength of an association increases not only when two events are presented together, but also when both stimuli are expected to occur but are absent. That is, presentation of an associate of a target stimulus in the absence of the target (Y) allows modification of all associations to the target. Thus, following blocking treatment, Stimulus $\mathrm{Y}$ is expected to have a weak association to the US because of X's having acquired most of the available associative strength. Subsequent extinction of the blocking stimulus (X) should result in an increase in the strength of the previously blocked Stimulus-Y-US association because both $\mathrm{Y}$ and the US are expected when $\mathrm{X}$ is presented, due to their both having been previously paired with $\mathrm{X}$, but the two of them are absent. That is, for these modified models, blocking reflects a deficit in acquiring a $\mathrm{Y}-\mathrm{US}$ association, and increases in responding to $\mathrm{Y}$ mediated by posttraining extinction of the blocking stimulus $(\mathrm{X})$ reflect new learning between expected but absent stimuli. The development of modified informational models has made it increasingly difficult to discriminate, through posttraining manipulations of the competing stimuli, between views of stimulus competition as an acquisition deficit (i.e., informational models) and views of stimulus competition as a performance deficit (e.g., the comparator hypothesis). Thus, it is necessary to develop new approaches to discriminate between these views.

The present report analyzes associative changes to the blocking stimulus as a result of blocking treatment (i.e., $\mathrm{X}$-US followed by XY-US, testing on $X$ ). For models based on the informational hypothesis, the X-US pairings of the first phase of a blocking design should result in a robust association between X and the US. Further $\mathrm{XY}-\mathrm{US}$ pairings in Phase 2 should not weaken this $\mathrm{X}-\mathrm{US}$ association; rather, they should strengthen it, because of the additional $\mathrm{X}$-US pairings within the XY-US pairings. The comparator hypothesis predicts a different result. According to the comparator hypothesis, the $\mathrm{X}-\mathrm{US}$ and the $\mathrm{Y}-\mathrm{US}$ associations will be acquired independently of each other. However, at the moment of testing $\mathrm{X}$, the strength of the X-US association will be compared with the strength of the association between X's comparator stimulus and the US (i.e., Y-US). ${ }^{2}$ Thus, conditioned responding to $\mathrm{X}$ should be greater after $\mathrm{X}$-US treatment (Phase 1 of the blocking design) than after XY-US treatment (Phase 2) because, in the latter case, the Y-US association will attenuate responding to $\mathrm{X}$ at test. The existing literature provides some support for this prediction of the comparator hypothesis. Hall, Mackintosh, Goodall, and Dal Martello (1977) reported that rats exposed to a blocking procedure in which the blocking stimulus was a soft tone exhibited attenuated conditioned responding to the blocking stimulus (on a test trial with the blocking stimulus alone) if it was later reinforced in compound with a more salient blocked stimulus (a bright light), relative to an otherwise equivalent stimulus that was never trained in compound. Hall et al. explained their results within an attentional version of the informational hypothesis, according to which a stimulus of low salience acquires behavioral control if it is the only available predictor of the reinforcement but loses this control if it is presented in compound with a second, more salient stimulus that itself then comes to control behavior. Notably, this account anticipates a loss of responding to the blocking stimulus only when the blocking stimulus is less salient than the blocked stimulus. In contrast, the comparator hypothesis anticipates a loss of responding to the blocking stimulus even when the blocking stimulus is not less salient than the blocked stimulus, although the effect should not be as great as when the blocking stimulus is less salient than the blocked stimulus. The present experiment was conducted to evaluate these differential predictions with stimuli that were of equal salience. 
Four groups of rats received pairings of Stimulus $\mathrm{X}$ and the US during Phase 1 (X-US). During Phase 2, the rats in the experimental condition received pairings of the XY compound and the US (XY-US), whereas the rats in the control condition received pairings of a compound composed of novel elements and the US (ZY-US). Blocking of $\mathrm{Y}$ should be observed in the experimental condition, in which $\mathrm{Y}$ was paired with a stimulus $(\mathrm{X})$ that had already been trained as a predictor of the US. For half of the animals in each of the experimental and control conditions, Y was of higher salience than X (high condition), whereas for the remaining half, $\mathrm{Y}$ and $\mathrm{X}$ were of similar salience (similar condition; see Table 1). Thus, the present study was a 2 (condition: experimental vs. control) $\times 2$ (salience of the blocked stimulus: high vs. similar) design. Decreases in conditioned responding to $\mathrm{X}$ in the high-experimental group (as compared with the high-control group) would be consistent with both the acquisition-focused and the performance-focused (e.g., comparator) views of stimulus competition. In contrast, decreases in responding to $\mathrm{X}$ in the similar-experimental group (as compared with the similar-control group) would be consistent only with the comparator view of stimulus competition.

\section{METHOD}

\section{Subjects}

The subjects were 48 male (195-360 g) and 48 female (176$356 \mathrm{~g}$ ) experimentally naive Sprague Dawley rats bred in our colony. The experiment was performed in two replications, each with 48 subjects ( 24 males and 24 females). The subjects were individually housed and maintained on a 16:8-h light:dark cycle; experimental sessions occurred midway through the light portion. The subjects had free access to food in the home cage. Prior to initiation of the experiment, water availability was progressively reduced to $30 \mathrm{~min}$ per day, approximately $2 \mathrm{~h}$ after any scheduled treatment.

\section{Apparatus}

Twelve experimental chambers of two different types were used: six rectangular (R) and six V-shaped (V), which were counterbalanced within groups. The use of two different chambers was due to the available apparatus and was not relevant to the present topic of concern. Chamber $\mathrm{R}$ was a clear Plexiglas enclosure, measuring $23.0 \times 8.25 \times 13.0 \mathrm{~cm}(1 \times \mathrm{w} \times \mathrm{h})$. The floor of Chamber $\mathrm{R}$ was constructed of stainless steel rods, which permitted delivery of constant-current footshock. Chamber V was a 22.1-cm-long box in a vertically oriented truncated-V shape $(25.3-\mathrm{cm}$ height, $21.3 \mathrm{~cm}$ wide at the top, $5.1 \mathrm{~cm}$ wide at the bottom). The floor and sides
}

were constructed of stainless steel sheets, and the ceiling was clear Plexiglas. The floor consisted of two parallel metal plates, each $2.0 \mathrm{~cm}$ wide, with a $1.1-\mathrm{cm}$ gap between them, which permitted delivery of constant-current footshock.

Each chamber was housed in a separate dimly illuminated environmental isolation chest and was equipped with a water-filled lick tube that extended $1 \mathrm{~cm}$ from the rear of a cylindrical recessed area, $4.5 \mathrm{~cm}$ in diameter, left-right centered in one short wall, with its axis perpendicular to the wall and positioned with its center $4.25 \mathrm{~cm}$ above the chamber's floor. Each niche had a horizontal infrared photobeam transversing it $1 \mathrm{~cm}$ in front of the lick tube. To drink from the tube, the subjects had to insert their heads into the niche, thereby breaking the photobeam. The amount of time that presentation of the test stimulus caused the subjects to cease breaking the photobeam (interrupt drinking) served as our dependent variable.

Three speakers were mounted on different walls of each environmental chest. Each speaker could deliver a different auditory stimulus: a click train (6/sec), a complex tone $(800$ and $1000 \mathrm{~Hz}$ simultaneously), and white noise. Ventilation fans in each chest provided a constant 76-dB background noise. When delivered, the white noise and the tone were approximately $6 \mathrm{~dB}$ above this background noise; click trains were approximately 20 or $6 \mathrm{~dB}$ above the background noise in the high and the similar conditions, respectively.

\section{Procedure}

The subjects were randomly assigned to one of four groups: high-experimental, high-control, similar-experimental, and similarcontrol, counterbalanced for sex $(n \mathrm{~s}=24)$. In the high conditions, Stimuli $\mathrm{X}$ and $\mathrm{Z}$ were the tone and the white noise, counterbalanced within groups; for the high-experimental condition, for half of the subjects $\mathrm{X}$ was the tone, and for the other half $\mathrm{X}$ was the noise. $\mathrm{Y}$ was the high-intensity click train. In the similar conditions, Stimuli $\mathrm{X}, \mathrm{Y}$, and $\mathrm{Z}$ were the tone, the white noise, and the moderate intensity click train, respectively, all counterbalanced within groups. All the stimuli were $10 \mathrm{sec}$ in duration. The US was a $0.5-\mathrm{sec}, 0.8-\mathrm{mA}$ footshock. All the sessions were $60 \mathrm{~min}$ in duration, and no lick tubes were available in the training chambers unless otherwise noted (see Table 1).

Acclimation. On Day 1, all the subjects were acclimated to the experimental context. The subjects had access to the lick tubes, and no nominal stimuli were presented.

Blocking treatment. On Days 2 and 3, all the subjects were presented with four daily X-US pairings. On Days 4 and 5, the subjects in the experimental groups received four daily XY-US pairings, whereas the subjects in the control groups received four daily $\mathrm{ZY}$-US pairings. Termination of the stimuli was immediately followed by the US. Mean intertrial interval was 14 min. Lick tubes were absent.

Reacclimation. On Days 6, 7, and 8, the subjects were exposed to the training context with free access to the water-filled lick tubes in order to restabilize baseline drinking, which might have been disrupted by the footshock US administered during training. No nominal stimuli were programmed to occur.

Table 1

Experimental Design

\begin{tabular}{lccccc}
\hline & \multicolumn{2}{c}{ Training } & & \multicolumn{2}{c}{ Testing } \\
\cline { 2 - 3 } \cline { 5 - 6 } \multicolumn{1}{c}{ Groups } & Phase 1 & Phase 2 & & Blocking Stimulus & Blocked Stimulus \\
\hline High-experimental & X-US & XY-US & & X & Y \\
High-control & X-US & ZY-US & X & Y \\
Similar-experimental & X-US & XY-US & & X & Y \\
Similar-control & X-US & ZY-US & X & Y
\end{tabular}

Note-In the high conditions, Stimulus $\mathrm{Y}$ was more salient than Stimuli $\mathrm{X}$ and $\mathrm{Z}$ (higher salience is denoted by boldface); in the similar conditions, Stimuli X, Y, and $\mathrm{Z}$ were of similar salience. US represents the footshock unconditioned stimulus. Order of test was counterbalanced within groups. 
Testing. On Day 9 during 16-min sessions, half of the subjects in each group were tested for conditioned lick suppression to $\mathrm{X}$, whereas the other half were tested for conditioned lick suppression to Y; on Day 10, the test stimuli were reversed. Thus, all the subjects were tested on $\mathrm{X}$ and $\mathrm{Y}$. Time spent drinking by each subject upon placement in the test chamber was recorded. After five cumulative seconds of licking in the absence of any nominal stimulus (baseline scores), the test stimulus was presented; thus, all the subjects were drinking at test stimulus onset. Time to complete five additional cumulative seconds of licking in the presence of the test stimulus was recorded. The latter latencies presumably reflected the subjects' fear of the test stimulus (i.e., expectancy of the footshock). On Day 9, all the subjects were exposed to $15 \mathrm{~min}$ of the test stimulus; this was intended to control for possible generalized extinction to the stimulus tested on Day 10. On Day 10, completion of five cumulative seconds of licking in the presence of the test stimulus terminated the session.

Following the convention of our laboratory, all the animals taking over $60 \mathrm{sec}$ to complete their baseline licking during testing were eliminated because such long latencies reflect unusual fear of the context (baseline criterion). One subject from each of the high-experimental and similar-control groups was excluded from the analyses by this criterion. All the test scores were converted to log seconds (base 10) to better meet the assumptions of parametric statistical tests.

\section{RESULTS AND DISCUSSION}

Blocking (i.e., attenuated conditioned responding to $\mathrm{Y}$ in the experimental group, as compared with the control group) was observed in the similar condition, but not in the high condition. Of greater interest, consistent with the comparator hypothesis predictions, responding to the blocking stimulus $(\mathrm{X})$ was reduced in both the highexperimental and similar-experimental groups, as compared with their respective control conditions (see Figure 1). The following analyses support these conclusions.
A 2 (replication) $\times 2$ (experimental condition) $\times 2$ (salience) analysis of variance (ANOVA) performed to assess possible differences in drinking behavior prior to the presentation of $\mathrm{X}$ yielded a main effect of replication $\left[F(1,86)=11.89, M S_{\mathrm{e}}=0.05, p<.001\right]$, a main effect of salience $(F=6.52, p<.05)$, and no interactions $(F \mathrm{~s}<$ $0.93, p>.34)$. A similar ANOVA performed to assess possible differences in drinking behavior prior to the presentation of $\mathrm{Y}$ yielded a main effect of replication $\left[F(1,86)=6.52, M S_{\mathrm{e}}=0.04, p<.05\right]$ and a replication $\times$ condition $\times$ salience interaction $\left[F(1,86)=10.75, M S_{\mathrm{e}}=\right.$ $0.04, p<.01]$. That is, across replications the conditions differed in fear to the context. To control for these differences, we included replication as a factor in our analyses and used test trial pre-CS scores as a covariant in the analysis of CS scores.

A 2 (replication) $\times 2$ (experimental condition) $\times 2$ (salience) analysis of covariance (ANCOVA) performed on the scores recorded during the $\mathrm{Y}$ test yielded main effects of replication, condition, and salience $\left[F_{\mathrm{S}}(1,85)=\right.$ $5.13,8.95$, and $34.30, M S_{\mathrm{e}}=0.15$, all $\left.p \mathrm{~s}<.05\right]$ and a condition $\times$ salience interaction $[F(1,85)=5.04, p<.05]$. Planned comparisons using the error term from this ANCOVA revealed that blocking to $\mathrm{Y}$ occurred when $\mathrm{Y}$ and $\mathrm{X}$ were of similar salience [similar condition; $F(1,85)=14.27, p<.001]$, but not when $\mathrm{Y}$ was more salient than $\mathrm{X}$ [high condition; $F(1,85)=0.27, p>.6$ ].

A 2 (replication) $\times 2$ (experimental condition) $\times 2$ (salience) ANCOVA performed on the scores recorded during the $\mathrm{X}$ test yielded main effects of replication and condition $[F \mathrm{~s}(1,85)=7.02$ and 12.56 , respectively, $\left.M S_{\mathrm{e}}=0.15, p \mathrm{~s}<.01\right]$ and no other main effect or interaction (all $F \mathrm{~s}<1$ ). Planned comparisons derived from

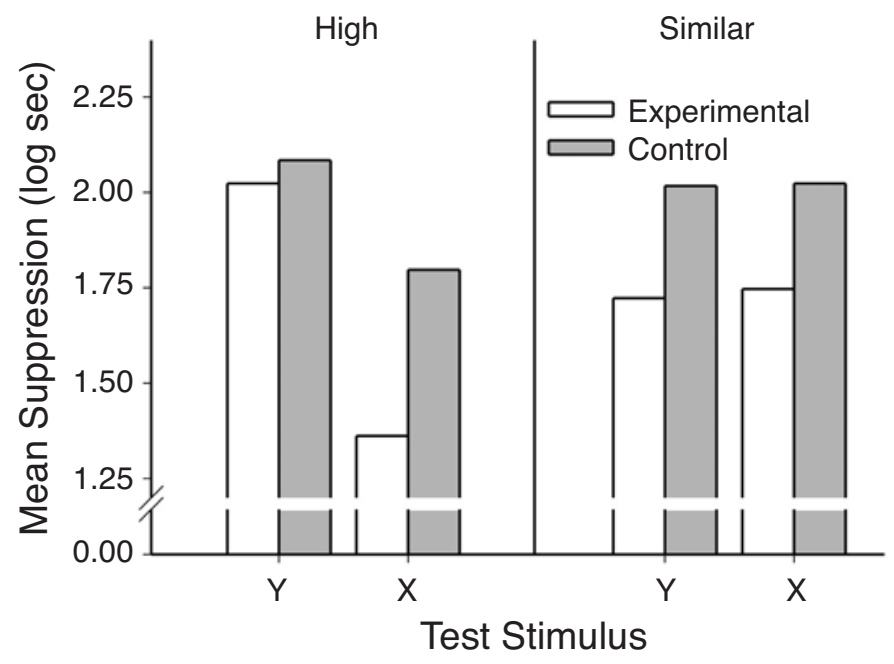

Figure 1. Mean suppression to the blocked stimulus, Y, and the blocking stimulus, $X$. The left side of the figure presents responding in the high condition, in which the blocked stimulus (Y) was of higher salience than the blocking stimulus $(X)$; the right side of the figure presents responding in the similar condition, in which salience of the the blocked stimulus was similar to that of the blocking stimulus. 
this ANCOVA revealed that conditioned responding to $\mathrm{X}$ was reduced after compound training with $\mathrm{Y}$ in both the high and the similar conditions $\left[F_{\mathrm{s}}(1,85)=6.71\right.$ and 5.93, respectively, $p$ s $<.05]$.

The blocking stimulus, $\mathrm{X}$, blocked conditioned responding to $\mathrm{Y}$ in the similar, but not in the high, condition. This failure of blocking can be due to at least three factors. First, the to-be-blocked stimulus, Y, was of higher salience than the blocking stimulus, $X$, which could have distracted the subjects from X during Phase 2 . Second, generalization decrement was likely greater for $\mathrm{Y}$ in the high-experimental condition than in the similar-experimental condition. Third, the number of Phase 2 compound pairings was greater than that in usual blocking designs, and extended compound training is known to attenuate blocking (e.g., Azorlosa \& Cicala, 1986). Usually, the number of blocking-stimulus-US pairings during Phase 1 is three or four times greater than the number of compound-US pairings during Phase 2. In this experiment, as well as in the experiments reported by Hall et al. (1977), the numbers of Phase 1 and Phase 2 trials were similar. We chose these parameters not only to parallel those used by Hall et al., but also because we anticipated that they were more appropriate for showing reduced responding to the blocking stimulus than the usual blocking parameters (a larger number of compound trials should allow for stronger Y-US associations to compete with the $\mathrm{X}$-US association).

A notable feature of the procedure was that $\mathrm{Y}$ was counterbalanced with $\mathrm{X}$ and $\mathrm{Z}$ in the similar condition, but not in the high condition. Counterbalancing was not done in the high condition because we wanted to replicate the procedure of Hall et al. (1977). This raises the possibility that the differences between the high and the similar conditions in conditioned responding to $\mathrm{X}$ and $\mathrm{Y}$ did not arise uniquely from the differences in the salience of Y. However, these differences are not important to our central finding. In both the high and the similar conditions, reduced responding to $\mathrm{X}$ was observed in the experimental group relative to its own control group. This difference in the high condition merely replicates Hall et al. The important observation here is the lower conditioned responding to $\mathrm{X}$ by the experimental subjects relative to the control subjects in the similar condition, in which $\mathrm{Y}$ was fully counterbalanced with $\mathrm{X}$ and $\mathrm{Z}$. This decrease in responding to the blocking stimulus in the similar condition cannot be explained by differences in the salience of $\mathrm{X}$ and $\mathrm{Y}$, as was suggested by Hall et al., although the tendency for a greater decrease in responding to the blocking stimulus in the high-experimental group, as compared with the similar-experimental group, may have been due to the greater salience of $Y$ in the high condition. That is, after the Phase $1 \mathrm{X}$-US pairings, compound training of $\mathrm{X}$ and $\mathrm{Y}$ with the US did not enhance responding to $\mathrm{X}$ but reduced it even in the similar condition. Thus, compound training, and not just the higher salience of $\mathrm{Y}$, seems to account for a significant fraction of this decrement in responding to the blocking stimulus.
In summary, with a design that resembled the traditional two-phase blocking designs (i.e., $\mathrm{X}-\mathrm{US}$ followed by XY-US, as compared with X-US followed by ZYUS), we observed that conditioned responding to the Blocking Stimulus $\mathrm{X}$ after compound training with $\mathrm{Y}$ was weaker than responding to $\mathrm{X}$ when $\mathrm{X}$ was not trained in compound. The explanation provided by Hall et al. (1977), based on the higher salience of the blocked stimulus reducing the previously acquired responding to the blocking stimulus, could explain the results from the high condition, but not the results from the similar condition, because all the stimuli were of similar salienceindeed, counterbalanced. In the similar condition, not only did the blocking stimulus, $\mathrm{X}$, attenuate (block) responding to the added stimulus, Y, but also the blocked stimulus, $\mathrm{Y}$, reduced (i.e., "blocked") responding to $\mathrm{X}$. This result is at odds with the assumptions of traditional (e.g., Mackintosh, 1975; Pearce, 1987; Rescorla \& Wagner, 1972; Wagner, 1981) and more recent (e.g., Dickinson \& Burke, 1996; Van Hamme \& Wasserman, 1994) associative learning models that are based on the informational hypothesis. According to these models, conditioned responding to $\mathrm{X}$ in the experimental condition should be similar to or greater than, not weaker than, responding to $\mathrm{X}$ in the control condition, in which $\mathrm{X}$ did not receive further compound training.

In contrast, some performance-focused views anticipate these results. For example, the comparator hypothesis (Miller \& Matzel, 1988) assumes that associations are learned through contiguity and that conditioned responding to a target stimulus depends on a comparison between the strength of the target-stimulus-US association and the strength with which other stimuli that were present during training of the target stimulus activate a representation of the US. Thus, in the experimental groups, $\mathrm{X}$ blocked responding to $\mathrm{Y}$ because the $\mathrm{X}-\mathrm{US}$ association attenuates the impact on responding of the $\mathrm{Y}-\mathrm{US}$ association. Conversely and more central to our present concern, when the blocking stimulus, $\mathrm{X}$, was presented at test, the $\mathrm{Y}-\mathrm{US}$ association attenuated the impact on responding of the X-US association. This is consistent with the comparator hypothesis' assumption that the reduced responding observed in stimulus competition reflects a deficit in responding and not a deficit in learning.

\section{REFERENCES}

Arcediano, F., Escobar, M., \& Matute, H. (2001). Reversal from blocking in humans as a result of posttraining extinction of the blocking stimulus. Animal Learning \& Behavior, 29, 354-366.

Azorlosa, J. L., \& CicAla, G. A. (1986). Blocking of conditioned suppression with 1 or 10 compound trials. Animal Learning \& Behavior, 14, 163-167.

BlAISDELl, A. P., Gunther, L. M., \& Miller, R. R. (1999). Recovery from blocking achieved by extinguishing the blocking CS. Animal Learning \& Behavior, 27, 63-76.

BuSH, R. R., \& MOSTELLER, F. (1951). A mathematical model for simple learning. Psychological Review, 58, 313-323.

Cole, R. P., Barnet, R. C., \& Miller, R. R. (1995). Effect of relative 
stimulus validity: Learning or performance deficit? Journal of Experimental Psychology: Animal Behavior Processes, 21, 293-303.

Denniston, J. C., Savastano, H. I., \& Miller, R. R. (2001). The extended comparator hypothesis: Learning by contiguity, responding by relative strength. In R. R. Mowrer \& S. B. Klein (Eds.), Handbook of contemporary learning (pp. 65-117). Mahwah, NJ: Erlbaum.

Dickinson, A., \& Burke, J. (1996). Within-compound associations mediate the retrospective revaluation of causality judgments. Quarterly Journal of Experimental Psychology, 49B, 60-80.

Hall, G., Mackintosh, N. J., Goodall, G., \& Dal Martello, M. (1977). Loss of control by a less valid or by a less salient stimulus compounded with a better predictor of reinforcement. Learning \& Motivation, 8, 145-158.

KAMIN, L. J. (1968). "Attention-like" processes in classical conditioning. In M. R. Jones (Ed.), Miami Symposium on the prediction of behavior: Aversive stimulation (pp. 9-31). Miami: University of Miami Press.

Kaufman, M. A., \& Bolles, R. C. (1981). A nonassociative aspect of overshadowing. Bulletin of the Psychonomic Society, 18, 318-320.

Larkin, M. J. W., Aitken, M. R. F., \& Dickinson, A. (1998). Retrospective revaluation of causal judgments under positive and negative contingencies. Journal of Experimental Psychology: Learning, Memory, \& Cognition, 24, 1331-1352.

MACKINTOSH, N. J. (1975). A theory of attention: Variations in the associability of stimuli with reinforcement. Psychological Review, 82, 276-298.

Matzel, L. D., Schachtman, T. R., \& Miller, R. R. (1985). Recovery of an overshadowed association achieved by extinction of the overshadowing stimulus. Learning \& Motivation, 16, 398-412.

Miller, R. R., \& Matzel, L. D. (1988). The comparator hypothesis: A response rule for the expression of associations. In G. H. Bower (Ed.), The psychology of learning and motivation (Vol. 22, pp. 5192). San Diego: Academic Press.

Pavlov, I. (1927). Conditioned reflexes (G. V. Anrep, Trans.). London: Oxford University Press, Clarendon Press.

Pearce, J. M. (1987). A model of stimulus generalization for Pavlovian conditioning. Psychological Review, 94, 61-73.

RANDICH, A., \& LoLoRDO, V. M. (1979). Associative and nonassociative theories of the UCS preexposure of phenomenon: Implications for Pavlovian conditioning. Psychological Bulletin, 86, 523-548.

Rauhut, A. S., McPhee, J. E., DiPietro, N. T., \& AYres, J. J. B. (2000). Conditioned inhibition training of the competing cue after compound conditioning does not reduce cue competition. Animal Learning \& Behavior, 28, 92-108.

RESCORLA, R. A., \& WAGNER, A. R. (1972). A theory of Pavlovian conditioning: Variations in the effectiveness of reinforcement and nonreinforcement. In A. H. Black \& W. F. Prokasy (Eds.), Classical conditioning II: Current research and theory (pp. 64-99). New York: Appleton-Century-Crofts.

Van Hamme, L. J., \& Wasserman, E. A. (1994). Cue competition in causality judgments: The role of nonpresentation of compound stimulus elements. Learning \& Motivation, 25, 127-151.

WAGNER, A. R. (1981). SOP: A model of automatic memory processing in animal behavior. In N. E. Spear \& R. R. Miller (Eds.), Information processing in animals: Memory mechanisms (pp. 5-47). Hillsdale, NJ: Erlbaum.

Wagner, A. R., Logan, F. A., Haberlandt, K., \& Price, T. (1968). Stimulus selection and a "modified continuity theory." Journal of Experimental Psychology, 76, 171-180.

WASSERMAn, E. A., \& BerGLAN, L. R. (1998). Backward blocking and recovery from overshadowing in human causal judgment: The role of within-compound associations. Quarterly Journal of Experimental Psychology, 51B, 121-138.

\section{NOTES}

1. Specifically, the comparator hypothesis assumes that responding to the target stimulus depends on the comparison of the strength of activation of the US representation by the target-stimulus-US association (direct activation) and the strength of activation of the US representation by the comparator-stimulus-US association (indirect activation). The strength of activation of the US through the indirect pathway is proportional to the product of the strength of association between the target stimulus and its comparator stimulus and the strength of association between the comparator stimulus and the US.

2. Note that the context can also serve as a comparator stimulus in this situation (e.g., Denniston et al., 2001). However, because of the long intertrial intervals (constituting extinction of the context) and the low salience of the context, its impact in the present situation was assumed to be minimal. For simplicity in the present situation, the role of the context as comparator stimulus was ignored.

(Manuscript received September 3, 2003; revision accepted for publication February 20, 2004.) 